\title{
EVALUATION OF TWO NESTED PCR-BASED DIAGNOSTIC ASSAYS FOR PLASMODIUM FALCIPARUM INFECTION
}

\author{
KANYANAN KRITSIRIWUTHINAN*, KANTHIMA CHOOSANG, SAKONE SUNANTARAPORN
}

Department of , Faculty of Medical Technology, Rangsit University, Pathumtani 12000, Thailand. Email: kanyanan_dk11@hotmail.com Received: 23 May 2017, Revised and Accepted: 23 June 2017

ABSTRACT

Objective: The majority of malaria cases and deaths are caused by Plasmodium falciparum. The rapid and accurate diagnosis is very important for malaria treatment and control. The aim of this study was to evaluate two nested polymerase chain reaction (PCR)-based methods (protocol A and protocol B) for P. falciparum infection, diagnosis in Thailand.

Methods: A total of 90 dried blood spot samples were investigated. The samples composed of P. falciparum-, Plasmodium vivax-infected blood and normal human blood samples. The microscopic examination was used as gold standard.

Results: The results showed the sensitivity of $100 / 83.33 \%$, specificity of $100 / 100 \%$, and accuracy of $100 / 94.44 \%$ for protocol A and protocol B, respectively. The analytical sensitivity of protocol A and protocol B was 0.625 and 6.25 parasites/ $\mu$ l, respectively. The comparison among microscopic examination, protocol A and protocol B by statistical analysis, found that they were not a significant difference. The agreements between each method were good. The kappa value between protocol A and protocol B was 0.87 , protocol A and microscopy was 1.00 , and protocol B and microscopy was 0.87.

Conclusion: The results demonstrated that protocol A should be used for further development of $P$. falciparum diagnosis in Thailand, especially in case of low parasitemia such as asymptomatic infection and for screening blood donors.

Keywords: Nested polymerase chain reaction, Plasmodium falciparum, Malaria, Thailand.

(C) 2017 The Authors. Published by Innovare Academic Sciences Pvt Ltd. This is an open access article under the CC BY license (http://creativecommons. org/licenses/by/4. 0/) DOI: http://dx.doi.org/10.22159/ajpcr.2017.v10i10.20156

\section{INTRODUCTION}

Malaria is a major public health problem worldwide, especially in tropical and subtropical areas. Approximately 3.2 billion people are at risk of malarial infection and deaths [1]. Malarial infection is a mosquito-borne disease caused by the protozoan parasite belonging to the Plasmodium genus, which human malaria consists of five species are Plasmodium falciparum, Plasmodium vivax, Plasmodium ovale, Plasmodium malariae, and Plasmodium knowlesi. P. falciparum could result in a severe and complications in malaria patients, such as cerebral malaria [2]. In Thailand, several reports demonstrated that the $P$. falciparum has high rates of antimalarial drug resistance and it is a major of morbidity and mortality $[3,4]$.

The accurate and early diagnosis of malaria is useful for treatment, prevention, and reducing malaria transmission. The gold standard of laboratory diagnostic method for malarial infection is based on microscopic examination of Giemsa-stained thick and thin blood smears. However, the limitations of microscopy are the requirement of skill and experience of the investigators. In addition, low sensitivity (100-200 parasites/ $\mu \mathrm{l}$ of blood), time-consuming, and irregularity in species identification have been reported [5]. Hence, mixed infections have been found to misdiagnose. Alternative methods, such as rapid diagnostic tests (RDTs), were developed for detection of parasite-specific antigens in the blood malaria patients. RDTs based on detecting histidine-rich protein 2 (pfHRP2), an antigen-specific only $P$. falciparum, and non-falciparum malaria have been developed to target the conserved region of Plasmodium lactate dehydrogenase (pLDH) [6-8]. However, RDTs have low sensitivity for lowlevel parasitemia cases. Furthermore, they have shown the false-positive responses due to the persistence of the pfHRP2 antigen in the blood [9]

Polymerase chain reaction (PCR) has been extensively used for malaria diagnosis. Several PCR-based assays include conventional
PCR [10], multiplex PCR [11], loop-mediated isothermal amplification (LAMP) [12], nested PCR [13-16], semi-nested PCR [17], and real-time PCR [18]. PCR has shown to be good alternative methods, because of the high sensitivity and specificity. These methods could be used for identification of malaria parasite and could detect malaria parasites in mixed infections and submicroscopic parasitemia better than microscopic examination and RDTs $[19,20]$. Nested PCR is considered to be a sensitive and specific method for detecting the malaria parasite, and it is also valuable in epidemiological survey, as previously described [13]. Due to various primer sets were reported in various areas with varying sensitivity and specificity $[13,21]$. Hence, in the present study, we compared the sensitivity, specificity, and accuracy of two nested PCRs using light microscopic examination as the reference method. The two nested PCRs based on 18S ribosomal RNA (18S rRNA) gene, using two different primer sets for detecting $P$. falciparum in dried blood samples obtained from malaria patients.

\section{MATERIALS AND METHODS}

\section{Blood sample collection}

A total of 90 blood samples consisted of $P$. falciparum-infected blood $(\mathrm{n}=30), P$. vivax-infected blood $(\mathrm{n}=30)$, and normal human blood $(\mathrm{n}=30)$. The samples were collected from Mae Hong Son, Tak, Kanchanaburi and Yala provinces, Thailand. Thick and thin blood films were prepared from each sample for Giemsa staining, $200 \mu \mathrm{l}$ of EDTA whole blood was dropped on Whatman filter paper, the dried blood spot (DBS) samples were stored in ziplock plastic bags at room temperature before transporting to a laboratory, and then, PCR determinations were assessed. The study was approved by the Ethics Committee of Rangsit University.

\section{Microscopic examination}

Both thick and thin blood films were stained with 3\% Giemsa solution (Merck) for 40 minutes. Species identification and the parasite 
density were examined by microscopy using the $\times 100$ oil immersion objective lens. The parasite density (parasites/ $\mu$ l) was detected by counting 1,000 red blood cells from each positive thin blood film, and the number of red blood cell density was estimated as $5 \times 10^{6}$ for the parasites per microliter blood calculation (https://www.cdc.gov/ $\mathrm{dpdx} /$ diagnosticprocedures/blood/microexam.html).

\section{DNA isolation from DBSs}

Parasite DNA was extracted from DBS, $200 \mu \mathrm{l}$ of phosphate buffered saline ( $\mathrm{pH}$ 7.2) was added in each sliced DBS for 10 minutes at room temperature, and then, $20 \mu \mathrm{l}$ of proteinase $\mathrm{K}$ solution $(25 \mathrm{mg} / \mathrm{ml})$ was added. After that, DNA was extracted using blood DNA extraction kit, Fermentas Gene JET ${ }^{\mathrm{TM}}$ (Thermo Fisher Scientific), following manufacturer's instructions. Purified DNA was eluted in $50 \mu \mathrm{l}$ of elution buffer and stored at $-20^{\circ} \mathrm{C}$ for the molecular technique processing.

\section{Nested PCR for P. falciparum detection}

In this study, the $P$. falciparum amplification by a nested PCR assay from two different sets of primers based on 18S rRNA genes was investigated. The first nested PCR (protocol A) was performed as previously described by Snounou et al., 1993 [13]. For the nest1 PCR reaction, $1 \mu \mathrm{l}$ of DNA was used in a total volume of $20 \mu \mathrm{l}$; the reaction mixture contained $10 \times$ PCR buffer with $\mathrm{MgCl}_{2}, 125 \mu \mathrm{m}$ of dNTP, $250 \mu \mathrm{m}$ of each primer (Table 1), and $0.4 \mathrm{U}$ of Taq DNA polymerase (i-Taq iNtRON Biotechnology/Korea). The PCR amplification conditions were as follows: Initial denaturation at $95^{\circ} \mathrm{C}$ for 5 minutes; 24 cycles of $94^{\circ} \mathrm{C}$ for 1 minute, $58^{\circ} \mathrm{C}$ for 2 minutes, and $72^{\circ} \mathrm{C}$ for 2 minutes with the final extension at $72^{\circ} \mathrm{C}$ for 5 minutes. A volume of $1 \mu \mathrm{l}$ of PCR amplicon from nest1 PCR was used as DNA template for nest2 PCR. Conditions and PCR reaction used for the second amplification were identical to that of the nest1 PCR, except that second round PCR amplification was conducted over 30 cycles.

The second nested PCR (protocol B) was carried out with primers as previously described by Mahajan et al., 2012 [21]. The PCR reaction was set up in a final volume of $25 \mu \mathrm{l}$ containing of $1 \mu \mathrm{l}$ of DNA template, $10 \times$ PCR buffer, $125 \mu \mathrm{m}$ of dNTP, $0.4 \mathrm{U}$ Taq DNA polymerase, and $250 \mu \mathrm{m}$ of each primer (Table 1). Cycling PCR conditions for both nest1 and nest2 amplifications were as follows: Initial denaturation at $94^{\circ} \mathrm{C}$ for 3 minutes; $94^{\circ} \mathrm{C}$ for 30 seconds, $59^{\circ} \mathrm{C}$ for 30 seconds, and $72^{\circ} \mathrm{C}$ for 30 seconds, 20 and 35 cycles of nest 1 and nest 2 PCR, respectively, and the final extension at $72^{\circ} \mathrm{C}$ for 7 minutes.

In this study, distilled water was the negative control and DNA extracted from $P$. falciparum K1 culture was used as the positive control. The PCR products were determined by $1.2 \%$ agarose gel electrophoresis, visualized under ultraviolet light after staining with ethidium bromide.

\section{Detection limit of nested PCR methods}

Limit of detection of two nested PCRs (protocol A and protocol B) was performed to detect $P$. falciparum using the $P$. falciparum $\mathrm{K} 1$ culture $\left(6.25 \times 10^{4}\right.$ parasites/ $\left.\mu \mathrm{l}\right)$. The 10 -fold serial dilution $\left(10^{-1}-10^{-6}\right)$ was performed to containing $6.25 \times 10^{3}, 6.25 \times 10^{2}, 62.5,6.25,0.625$, and 0.0625 parasites $/ \mu \mathrm{l}$, and then, DNA was extracted from each dilution according to the protocol (Thermo Fisher Scientific). One microliter of each DNA sample was as used as DNA template for both nested PCR amplification. The limit of detection was the lowest number of parasitemia that positive by PCR tested. In addition, DNA samples isolated from $P$. falciparum $\left(6.25 \times 10^{2}\right.$ parasites $\left./ \mu \mathrm{l}\right)$, P. vivax, $P$. malariae, $P$. ovale, and human normal blood were also evaluated for the analytical specificity of both nested PCRs.

\section{Statistical analysis}

The evaluations of each test were performed with the results of microscopy as the gold standard. Sensitivity, specificity, positive and negative predictive value, and accuracy of the test were calculated using two-by-two tables. Kappa statistic was used for comparing the agreement against which might be expected by chance with ranged from 1 (perfect agreement), -1 (complete disagreement), and 0 indicated that no agreement.

\section{RESULTS}

\section{Detection limit and cross-amplification of nested PCR}

For the detection limit of nested PCR methods by protocol A and protocol using a DNA template extracted from $P$. falciparum $\mathrm{K} 1$ culture, the results demonstrated that the protocol A was more sensitive than protocol B. According to the protocol A could detect P. falciparum K1 culture as low as 0.625 parasite $/ \mu \mathrm{l}$, whereas the protocol B could amplify at 6.25 parasite/ $\mu$ l. Both nested PCR methods amplifying of 18S rRNA gene of $P$. falciparum showed the PCR product size of 205, $287 \mathrm{bp}$ for protocol A and B, respectively.

In this study, we determined the specificity of both nested PCR methods using the DNA of other Plasmodium spp. From clinical samples ( $P$. vivax, $P$. malariae, and $P$. ovale), P. falciparum $\mathrm{K} 1$ culture and human normal blood.Both nested PCRstargetingthe18SrRNA gene could amplify only the DNA of $P$. falciparum K1 culture and showed no crossamplification with other parasites and human normal blood DNA.

\section{Diagnostic sensitivity and specificity of nested PCR to detect} $P$. falciparum in clinical samples

A total of 90 DBS samples in the present study were obtained from blood of 60 patients who diagnosed with clinical symptoms, and microscopy from blood film that was confirmed with 30 samples of $P$. falciparum and 30 samples of $P$. vivax infections and 30 samples of human normal blood. Microscopic examination showed the average of parasitemia of 364.29 parasites/ $\mu \mathrm{l}$ (range 1.08-2183 parasites/ $\mu \mathrm{l}$ ) for the $P$. falciparum infection, and parasitemia in $P$. vivax infection was 30.80 parasites $/ \mu \mathrm{l}$ (range $0.0017-172.5$ parasites $/ \mu \mathrm{l}$ ).

Table 2 shows the sensitivities, specificities, and positive predictive values (PPV) and negative predictive values (NPV), and accuracies of two nested PCR methods compared with the microscopic examination to detect $P$. falciparum in clinical specimens. The protocol A showed $100 \%$ of the high diagnostic sensitivity, specificity, PPV, NPV, and accuracy. In addition, the diagnostic sensitivity and specificity of protocol B were $83.33 \%$ and $100 \%$, respectively. Moreover, the tests of PPV, NPV, and accuracy for protocol B were $100 \%, 92.31 \%$, and $94.44 \%$, respectively. When protocol $\mathrm{A}$ and protocol $\mathrm{B}$ were compared, the protocol A displayed more sensitivity of detection than the protocol B. 25 samples were detected by nested PCR using protocol B with showing 5 samples false negative. In addition, the comparison between microscopy, protocol A, and protocol B through statistical analysis was not different at the significant value $(p<0.05)$. The measure agreement

Table 1: Sequences of the primers used in this study

\begin{tabular}{llll}
\hline Methods & Primer sets & Primer sequence (5'-3') & References \\
\hline Protocol A & rPLU5 & CCT GTT GTT GCC TTA AAC TTC & [13] \\
& rPLU6 & TTA AAA TTG TTG CAG TTA AAA CG & \\
rFAL1 & TTA AAC TGG TTT GGG AAA ACC AAA TAT ATT & \\
Proto & ACA CAA TGA ACT CAA TCA TGA CTA CCC GTC & {$[21]$} \\
pPlF1 & GAA CGA GAT CTT AAC CTG CTA A & \\
& pPlrR1 & TCA GCA CAA TCT GAT GAA TCA T & \\
& Pf-F & ACA TAG GTA ACT ATA CAT TTA TTC AGT & \\
& Pf-R & AGC ATC AAA GAT ACA AAT ATA AGC A & \\
\hline
\end{tabular}


Table 2: The diagnostic performance of two nested PCR methods to detect $P$. falciparum compared to the microscopic examination

\begin{tabular}{|c|c|c|c|c|c|c|c|}
\hline \multirow[t]{2}{*}{ nPCR } & \multicolumn{2}{|c|}{ Microscopy } & \multirow[t]{2}{*}{ Sensitivity (\%) } & \multirow[t]{2}{*}{ Specificity (\%) } & \multirow[t]{2}{*}{ PPV (\%) } & \multirow[t]{2}{*}{ NPV (\%) } & \multirow[t]{2}{*}{ Accuracy (\%) } \\
\hline & Pf+ & Pf- & & & & & \\
\hline \multicolumn{8}{|c|}{ Protocol A } \\
\hline Pf- & 0 & 60 & & & & & \\
\hline \multicolumn{8}{|c|}{ Protocol B } \\
\hline $\mathrm{Pf}+$ & 25 & 0 & 83.33 & 100 & 100 & 92.31 & 94.44 \\
\hline $\mathrm{Pf}-$ & 5 & 60 & & & & & \\
\hline
\end{tabular}

nPCR: Nested polymerase chain reaction, Pf+: Plasmodium falciparum positive, Pf-: Plasmodium falciparum negative, PPV: Positive predictive value, NPV: Negative predictive value

of kappa values showed good agreements of $1.00,0.87$, and 0.87 for protocol A versus microscopy (Table 3), protocol B versus microscopy (Table 4), and protocol A versus protocol B (Table 5), respectively.

\section{DISCUSSION}

Microscopy is known to be the gold standard for malaria detection. However, this method has low specificity and sensitivity. Moreover, misdiagnosis of mix parasite infection has been reported [22]. Currently, the detection of $P$. falciparum infection has required the method that has high sensitivity and specificity, especially for a screening of the asymptomatic patients and blood donation [21]. PCR has been developed to detect the malaria parasite for increasing the sensitivity and specificity, including semi-nested PCR [17], nested PCR [13,23,15], and real-time PCR [18].

This study was conducted to evaluate the efficacy of nested PCR for detection of $P$. falciparum in Thailand, which protocol A as described by Snounou et al., 1993 [13], while the protocol B was carried out as described by Mahajan et al., 2012 [21]. The result of this study indicated that the nested PCR protocol A was more efficacy and superior for detection of $P$. falciparum over protocol B. The detection limit of this protocol was good and similar as found in previous nested PCR studies [5,23-25]

While both nested PCRs of protocol A and B used the same samples and DNA extraction method and were tested under appropriate conditions with the same reagents. Nested PCR of protocol A showed that it is useful for detecting asymptomatic infection, which is difficult to detect by microscopy because of low parasitemia [26].

In the present study, 5 samples were unable to detect $P$. falciparum by nested PCR protocol B in P. Falciparum positive by microscopy, but the nested PCR protocol A could be detected. This may be an effect of low malaria parasite presented in the samples, and it may be possible that the DNA templates of these 5 samples have some sequence variation, so the primer was not annealed with the DNA templates. In addition, several studies were described inconsistencies in malaria positive when reaction was performed using the nested PCR including lower of DNA yield from blood spot and presence of blood inhibitors such as hemoglobin, hem, immunoglobulin $\mathrm{G}$, and lactoferrin $[27,28]$.

The results revealed that the protocol $\mathrm{A}$ had a high sensitivity and specificity. Our result was similar to that of a previous report that used the nested PCR as described by Snounou et al., 1993 [13], mentioned by Anthony et al., 2013 [14]. A study reported by Li et al., 2014 [15], demonstrated that the nested PCR using blood filter paper samples had more sensitivity than microscopy for detecting Plasmodium infections. A report by Yentur Doni et al., 2016 [16], revealed that nested PCR has $100 \%$ sensitivity and $97.2 \%$ specificity.

Moreover, the present study was able to detect mixed infections (P. falciparum and P. vivax) in one sample by both nested PCRs, which were positive only $P$. vivax detected by microscopy. This suggested that it is possible for microscopic misdiagnosis occurs due to the dominance of one species over the other species $[29,30]$.
Table 3: Comparison between nested PCR protocol A and microscopy results

\begin{tabular}{lllll}
\hline Microscopy & \multicolumn{2}{l}{ PCR-protocol A } & Total & Kappa value/p value \\
\cline { 2 - 3 } & Positive & Negative & & \\
\hline Positive & 30 & 0 & 30 & $1.000 / 0.000$ \\
Negative & 0 & 60 & 60 & \\
Total & 30 & 60 & 90 & \\
\hline
\end{tabular}

PCR: Polymerase chain reaction

Table 4: Comparison between nested PCR protocol B and microscopy results

\begin{tabular}{lllll}
\hline Microscopy & \multicolumn{2}{l}{ PCR-protocol B } & Total & Kappa value/p value \\
\cline { 2 - 3 } & Positive & Negative & & \\
\hline Positive & 25 & 5 & 30 & $0.870 / 0.000$ \\
Negative & 0 & 60 & 60 & \\
Total & 25 & 65 & 90 & \\
\hline
\end{tabular}

PCR: Polymerase chain reaction

Table 5: Comparison of two nested PCR (protocol A versus protocol B) results

\begin{tabular}{lllll}
\hline PCR-protocol A & \multicolumn{2}{l}{ PCR-protocol B } & Total & $\begin{array}{l}\text { Kappa } \\
\text { value/p value }\end{array}$ \\
\cline { 2 - 3 } & Positive & Negative & & \\
\hline Positive & 25 & 5 & 30 & $0.870 / 0.000$ \\
Negative & 0 & 60 & 60 & \\
Total & 25 & 65 & 90 & \\
\hline
\end{tabular}

PCR: Polymerase chain reaction

In conclusion, we demonstrated that nested PCR by protocol A was sensitive and specific to diagnose malarial infection caused by P. falciparum, especially for submicroscopic infections. Furthermore, both nested PCRs can also be used in mixed infection detection and could be improved for screening blood donation. Due to its high sensitivity, this method could be useful for the epidemiological studies of malarial infection in Thailand.

\section{ACKNOWLEDGMENTS}

We would like to thank all of the medical technologists in hospitals for the assistance in sample collection and the $4^{\text {th }}$-year medical technology students of Rangsit University and Mr. Chaiyawut Kornkanok, Mr. Natthaphon Nenthuen, Ms. Tisa Jaroenwai, Ms. Phatharaphan Meedee, Ms. Wanwisa Pacharoensuk, and Mr. Sakarin Chaimongkol for laboratory assistance. We thank for Dr. Warunee Ngrenngarmlert (Mahidol University) for providing DNA of P. malariae and P. ovale. We also thank Dr. Sumalee Kamchonwongpaisan (National Center for Genetic Engineering and Biotechnology, Thailand) for kindly providing $P$. falciparum K1 strain. This work supported by Rangsit University fund. 


\section{REFERENCES}

1. WHO. World Malaria Report 2016. Geneva: World Health Organization; 2016.

2. Hora R, Kapoor P, Thind KK, Mishra PC. Cerebral malaria-clinical manifestations and pathogenesis. Metab Brain Dis 2016;31:225-37.

3. Mungthin M, Suwandittakul N, Chaijaroenkul W, Rungsrihirunrat K, Harnyuttanakorn P, Seugorn A, et al. The patterns of mutation and amplification of Plasmodium falciparum pfert and pfmdr1 genes in Thailand during the year 1988 to 2003. Parasitol Res 2010;107(3):539-45.

4. Na-Bangchang K, Muhamad P, Ruaengweerayut R, Chaijaroenkul W, Karbwang J. Identification of resistance of Plasmodium falciparum to artesunate-mefloquine combination in an area along the Thai-Myanmar border: Integration of clinico-parasitological response, systemic drug exposure, and in vitro parasite sensitivity. Malar J 2013;12(1):263.

5. Ndao M, Bandyayera E, Kokoskin E, Gyorkos TW, MacLean JD, Ward BJ. Comparison of blood smear, antigen detection, and nestedPCR methods for screening refugees from regions where malaria is endemic after a malaria outbreak in Quebec, Canada. J Clin Microbiol 2004;42(6):2694-700.

6. Ayoola A, Adewumi S, Oyedele O, Saidu B, Mustapha O, Adetoro B, et al. Relevance of rapid immunodiagnostic test kits in malaria diagnosis. Int J Curr Pharm Res 2015;7(4):9-10.

7. Pakalapati D, Garg S, Middha S, Kochar A, Subudhi AK, Arunachalam BP, et al. Comparative evaluation of microscopy, OptiMAL( $(\mathbb{R})$ and 18S rRNA gene based multiplex PCR for detection of Plasmodium falciparum and Plasmodium vivax from field isolates of Bikaner, India. Asian Pac J Trop Med 2013;6(6):346-51.

8. Sharma J. Prevalence of malaria cases in tea garden areas of lakhimpur district, Assam. Int J Pharm Pharm Sci 2014;6(8):571-3.

9. Laban NM, Kobayashi T, Hamapumbu H, Sullivan D, Mharakurwa S, Thuma PE, et al. Comparison of a PfHRP2-based rapid diagnostic test and PCR for malaria in a low prevalence setting in rural southern Zambia: Implications for elimination. Malar J 2015;14(1):25.

10. Cunha MG, Medina TS, Oliveira SG, Marinho AN, Póvoa MM, Ribeiro-dos-Santos AK. Development of a polymerase chain reaction (PCR) method based on amplification of mitochondrial DNA to detect Plasmodium falciparum and Plasmodium vivax. Acta Trop 2009;111(1):35-8

11. Stanis CS, Song BK, Chua TH, Lau YL, Jelip J. Evaluation of new multiplex PCR primers for the identification of Plasmodium species found in Sabah, Malaysia. Turk J Med Sci 2016;46(1):207-18.

12. Kongkasuriyachai D, Yongkiettrakul S, Kiatpathomchai W, Arunrut N. Loop-mediated isothermal amplification and LFD combination for detection of Plasmodium falciparum and Plasmodium vivax. Methods Mol Biol 2017;1572:431-43.

13. Snounou G, Viriyakosol S, Zhu XP, Jarra W, Pinheiro L, do Rosario VE, et al. High sensitivity of detection of human malaria parasites by the use of nested polymerase chain reaction. Mol Biochem Parasitol 1993;61(2):315-20.

14. Anthony C, Mahmud R, Lau YL, Syedomar SF, Sri La Sri Ponnampalavanar S. Comparison of two nested PCR methods for the detection of human malaria. Trop Biomed 2013;30(3):459-66.
15. Li P, Zhao Z, Wang Y, Xing H, Parker DM, Yang Z, et al. Nested PCR detection of malaria directly using blood filter paper samples from epidemiological surveys. Malar J 2014;13:175.

16. Yentur Doni N, Yildiz Zeyrek F, Seyrek A. Detection of Plasmodium using filter paper and nested PCR for patients with malaria in Sanliurfa, in Turkey. Malar J 2016;15(1):299.

17. Kritsiriwuthinan K, Ngrenngarmlert W. Molecular screening of Plasmodium infections among migrant workers in Thailand. J Vector Borne Dis 2011;48(4):214-8.

18. Taylor BJ, Martin KA, Arango E, Agudelo OM, Maestre A, Yanow SK. Real-time PCR detection of Plasmodium directly from whole blood and filter paper samples. Malar J 2011;10:244.

19. Imwong M, Nguyen TN, Tripura R, Peto TJ, Lee SJ, Lwin KM, et al. The epidemiology of subclinical malaria infections in South-East Asia: Findings from cross-sectional surveys in Thailand-Myanmar border areas, Cambodia, and Vietnam. Malar J 2015;14(1):385

20. Arango EM, Samuel R, Agudelo OM, Carmona-Fonseca J, Maestre A, Yanow SK. Molecular detection of malaria at delivery reveals a high frequency of submicroscopic infections and associated placental damage in pregnant women from northwest Colombia. Am J Trop Med Hyg 2013;89(1):178-83.

21. Mahajan B, Zheng H, Pham PT, Sedegah MY, Majam VF, Akolkar $\mathrm{N}$, et al. Polymerase chain reaction-based tests for panspecies and species-specific detection of human Plasmodium parasites. Transfusion 2012;52(9):1949-56.

22. Ebrahimzadeh A, Fouladi B, Fazaeli A. High rate of detection of mixed infections of Plasmodium vivax and Plasmodium falciparum in SouthEast of Iran, using nested PCR. Parasitol Int 2007;56(1):61-4.

23. Mehlotra RK, Lorry K, Kastens W, Miller SM, Alpers MP, Bockarie M, et al. Random distribution of mixed species malaria infections in Papua New Guinea. Am J Trop Med Hyg 2000;62(2):225-31.

24. Rubio JM, Benito A, Berzosa PJ, Roche J, Puente S, Subirats M, et al. Usefulness of seminested multiplex PCR in surveillance of imported malaria in Spain. J Clin Microbiol 1999;37(10):3260-4.

25. Hsiang MS, Lin M, Dokomajilar C, Kemere J, Pilcher CD, Dorsey G, et al. PCR-based pooling of dried blood spots for detection of malaria parasites: Optimization and application to a cohort of Ugandan children. J Clin Microbiol 2010;48(10):3539-43.

26. Coleman RE, Sattabongkot J, Promstaporm S, Maneechai N, Tippayachai B, Kengluecha A, et al. Comparison of PCR and microscopy for the detection of asymptomatic malaria in a Plasmodium falciparum/Vivax endemic area in Thailand. Malar J 2006;5:121.

27. Rådström P, Knutsson R, Wolffs P, Lövenklev M, Löfström C. PrePCR processing: Strategies to generate PCR-compatible samples. Mol Biotechnol 2004;26(2):133-46.

28. Steenkeste N, Incardona S, Chy S, Duval L, Ekala MT, Lim P, et al. Towards high-throughput molecular detection of Plasmodium: New approaches and molecular markers. Malar J 2009;8(1):86.

29. Gupta B, Gupta P, Sharma A, Singh V, Dash AP, Das A. High proportion of mixed-species Plasmodium infections in India revealed by PCR diagnostic assay. Trop Med Int Health 2010;15(7):819-24.

30. Bin Dajem SM. Molecular investigation of mixed malaria infections in southwest Saudi Arabia. Saudi Med J 2015;36(2):248-51. 